\title{
WestVirginiaUniversity
}

THE RESEARCH REPOSITORY @ WVU

Graduate Theses, Dissertations, and Problem Reports

2008

\section{Solubility of endodontic sealers in three common endodontic solvents}

Ryan W.L. Burleson

West Virginia University

Follow this and additional works at: https://researchrepository.wvu.edu/etd

\section{Recommended Citation}

Burleson, Ryan W.L., "Solubility of endodontic sealers in three common endodontic solvents" (2008). Graduate Theses, Dissertations, and Problem Reports. 2605.

https://researchrepository.wvu.edu/etd/2605

This Thesis is protected by copyright and/or related rights. It has been brought to you by the The Research Repository @ WVU with permission from the rights-holder(s). You are free to use this Thesis in any way that is permitted by the copyright and related rights legislation that applies to your use. For other uses you must obtain permission from the rights-holder(s) directly, unless additional rights are indicated by a Creative Commons license in the record and/ or on the work itself. This Thesis has been accepted for inclusion in WVU Graduate Theses, Dissertations, and Problem Reports collection by an authorized administrator of The Research Repository @ WVU. For more information, please contact researchrepository@mail.wvu.edu. 


\title{
Solubility of Endodontic Sealers in Three Common Endodontic Solvents
}

\author{
Ryan W.L. Burleson, D.D.S.
}

Thesis submitted to the

School of Dentistry

At West Virginia University

In Partial Fulfillment of the Requirements

For the Degree of

Master of Science

In

Endodontics

\author{
Michael D. Bagby, D.D.S., M.S., Ph.D., Chair \\ C. Russell Jackson, D.D.S., M.S. \\ Thomas F. Razmus, D.D.S, M.S.
}

Department of Endodontics

Morgantown, WV

2008 


\section{ABSTRACT \\ Solubility of Endodontic Sealers in Three Common Endodontic Solvents Ryan W.L. Burleson, D.D.S.}

The purpose of this study was to compare the solubility of four sealers in three common endodontic solvents at time intervals of five minutes, ten minutes, and twenty minutes. Recently, there has been a growing number of resin endodontic sealers with multiple studies looking at leakage and very few investigating their solubility. Three resin sealers (AH Plus, Epiphany, and EndoREZ) and one Grossman's formula sealer (Roth's 801) were tested with three common endodontic solvents (Chloroform, Eucalyptol, EndosolvR). All sealers were mixed according to the manufactors' specifications and placed into metal rings with openings of a diameter of twenty millimeters and height of two millimeters. Forty five samples of each sealer were allowed to set up for at least forty eight hours at thirty seven degrees Celsius with moisture present. A sample size of five was randomly assigned to one of the three solvents and one of the three time groups. The samples were weighed to the 0.0001 gram before being placed in the solvent. After being in the solvent, the samples were allowed to dry for twenty four hours before taking the final weight. An Excel spreadsheet was used to organize the data 
and calculate the differences in weight. The data was analyzed in a Split Plot ANOVA employing the REML method and Tukey's HSD. This was accomplished, by using the Jump software. Significance was determined at $\mathrm{P}<0.05$. The results indicated that multiple factors were significant, including solvent, sealer, and the amount of time. Chloroform was the most effective solvent and was the strongest at the twenty minutes time frame. As for the sealers, AH Plus and Roth's 801 were the most soluble sealers. Eucalyptol was effective only on Roth's 801 . The results of this study show that Epiphany and EndoREZ are not appreciably soluble and Endosolv-R was not clinically effective on any of the four sealers. 


\section{DEDICATION}

To my family, wife, and two children...

I could not have accomplished this without your love and support. Thank you for allowing me to reach for my dreams! 


\section{ACKNOWLEDGEMENTS}

I would like to acknowledge and thank the following people:

Dr. C. Russell Jackson for the amazing opportunity you afforded to me. I appreciate you passion and desire to teach and make others better. Thank you for your knowledge, guidance, friendship in life and dentistry.

Dr. Mike Bagby for providing me with the knowledge and leadership to finish this thesis and for serving on my committee.

Dr. Thomas Razmus for your advice, continued support, and serving on my thesis committee.

Dr. Mark Richey for being the best co-resident I could have and a great friend. There were many days I found comfort in our friendship and look forward to seeing you at meetings throughout our career. Good luck with everything in State College. Go Bucks!

Drs. Nic Taylor and Kent McBride for the guidance and examples you provided me during your senior year as residents. I hope to follow in your footsteps.

Drs. Albert Tomsic and Bryant Stowe for your advancement of my education. Your knowledge and skill made my second year pretty easy. I appreciate learning from your vast experiences.

Drs Neil Miller, Joe Wateska, Jason Hales, and Steven Moore for your teaching and inspiration during your time in the residency, while I was in dental school. You planted the seed to pursue Endodontics.

Cathy Myers and Gina White for all of your help, assistance, and conversation. I can honesty say it was a great two years. Thank you for your patience towards me, without you, my learning would have been lessened. 


\section{Table of Contents}

\begin{tabular}{|c|c|}
\hline ABSTRACT & ii \\
\hline DEDICATION & iv \\
\hline ACKNOWLEDGEMENTS & $\mathrm{V}$ \\
\hline TABLE OF CONTENTS & vi \\
\hline LIST OF FIGURES & vii \\
\hline LIST OF TABLES & vii \\
\hline CHAPTER I & 1 \\
\hline INTRODUCTION & 1 \\
\hline BACKROUND & 1 \\
\hline STATEMENT OF THE PROBLEM & 3 \\
\hline SIGNIFICANCE OF THE STUDY & 3 \\
\hline NULL HYPOTHESIS & 4 \\
\hline DEFINITION OF TERMS & 4 \\
\hline ASSUMPTIONS & 6 \\
\hline LIMITATIONS & 7 \\
\hline DELIMITATIONS & 7 \\
\hline CHAPTER II & 8 \\
\hline REVIEW OF LITERATURE & 8 \\
\hline CHAPTER III & 11 \\
\hline MATERIALS AND METHODS & 11 \\
\hline SAMPLE DESIGN & 12 \\
\hline SOLUBILITY METHODOLOGY & 12 \\
\hline DATA COLLECTION & 13 \\
\hline DATA ANALYSIS & 17 \\
\hline MATERIALS AND EQUIPMENT & 18 \\
\hline CHAPTER IV & 19 \\
\hline RESULTS AND DISCUSSION & 19 \\
\hline RESULTS & 19 \\
\hline SOLUBILITY OF SEALER & 20 \\
\hline SOLUBILITY OF SEALER IN DIFFERENT SOLVENTS & 21 \\
\hline SOLVENT ABILITY TO DISSOLVE ENDODONTIC SEALER & 22 \\
\hline SOLUBILITY AND TIME & 23 \\
\hline TIME AND SOLUBILITY INTERACTION & 24 \\
\hline DISCUSSION & 25 \\
\hline CHAPTER V & 27 \\
\hline SUMMARY AND CONCLUSIONS & 27 \\
\hline SUMMARY & 27 \\
\hline CONCLUSIONS & 28 \\
\hline REFERNCES & 29 \\
\hline CURRICULUM VITAE & 32 \\
\hline
\end{tabular}




\section{LIST OF FIGURES}

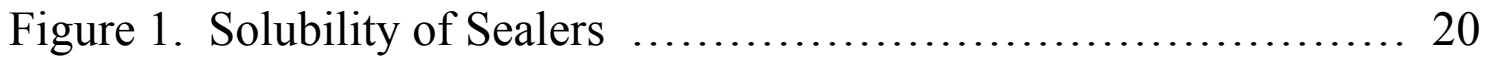

Figure 2. Solubility of Sealers in Different Solvents .................. 21

Figure 3. Solvents Ability to Dissolve Endodontic Sealer ............. 22

Figure 4. Solubility and Time …..................................... 23

Figure 5. Time and Solvent Interaction …........................... 24

\section{LIST OF TABLES}

Table 1. Sample Design …........................................ 12

Table 2. Data Table ….............................................. 13

Table 3. Oneway Analysis of Difference by Sealer …................. 20

Table 4. Oneway Analysis of Difference by Solvent …............. 22

Table 5. Oneway Analysis of Difference by Time …................ 23 


\section{Chapter 1: Introduction}

\section{Background}

Root canal therapy has been a very predictable mean of preserving natural teeth. A root canal is necessary when the dental pulp of the tooth becomes inflamed, infected, and sometimes needed for restorative reasons (eg. post placement). This can happen as a result of dental caries, dental restorative material placement, or trauma to the tooth. Endodontic therapy removes the damaged pulp, with chemical and mechanical instruments. Finally, the canals are filled with a core material and sealer. After effective root canal therapy a final restoration, which could be a crown or dental filling, is placed on the coronal portion of the tooth.

The success rate of initial root canal therapy is high, yet many teeth every year need to be retreated. Endodontic retreatment requires: finding all canals, removal of all previous filling material (both core material and sealer), reinstrumentation of the canal space and filling with new core material and sealer. Clinicians use solvents to soften the previous filling materials. Endodontic solvents need to be safe and effective at dissolving both gutta-percha, the most common core material, and sealer.

Endodontic sealers are designed to seal the gaps between the core materials and help prevent the root canal system from leakage. Currently, 
there is a push in the endodontic community to bond to the dentin walls, thus reducing the leakage of sealers. The most important seal comes from the restoration above the root canal filling, because it disallows or allows leakage from the oral cavity. Also, the literature has a fair amount of research on the solubility of gutta-percha in different endodontic solvents, but there are limited studies on the effects of solvent on root canal sealers. All popular filling techniques leave the apical portion and the walls with sealer, leaving it the last material to be removed in retreatment. The first time one views the walls of a canal with a surgical microscope he/she is surprised, to see what remains in the canal, after removing or believing to removed the previous root canal filling.

This study looked at the solubility of different sealers in three solvents, by looking at the weight of sealer before and after being immersed in one of the three solvents. The two most used solvents in dentistry are chloroform and eucalyptol. As the third sealer, we selected Endosolv-R (Septodont) because it is designed for removal of resin sealers. Hopefully, we have better insight on endodontic solvents and which sealers are more easily retreated. Until, we can ensure all canals are located and chemomechanically instrumented correctly we need to keep in mind the type of core materials and sealers being used and tested for further use. Efforts 
should continue to find a more universally effective solvent for use in root canal retreatment.

\section{Statement of the Problem}

Is there a difference of solubility among the different types of endodontic sealers in three of the most commonly used solvents (chloroform, eucalyptol, and Endosolv R)?

\section{Significance of the Study}

Currently, the hot topic with endodontic sealers is their leakage and how well they fill the canal preparation. The endodontic community is looking to completely fill the canal without any leakage, which is currently unachievable. Ideally, one would want to do this assuming all of the canals were located, instrumented mechanically and chemically correctly, and finally the proper restoration placed. But until all of these paradigms are achieved, it is important that these filling materials can be retreatable. With the current use of resin sealers, there have been very little studies that have looked at solubility of these root canal sealers. In certain areas of the country endodontists report from $25 \%$ to $80 \%$ of their cases being 
retreatments. It seems logical to test different endodontic sealers for their solubility in common endodontic solvents. Endodontists need more information regarding sealers and their solubility in endodontic solvents.

Even though it is impossible to know what sealer was initially used to treat a case, studies like this could lend insight about which sealers should be used, if a particular solvent is better than another, or if new solvents need to be sought after.

\section{Null Hypothesis}

There is no difference between different endodontic sealers when testing for solubility in three different solvents.

\section{Definition of Terms}

Root canal system $=$ a space containing the dental pulp within a tooth.

Root canal preparation $=\mathrm{a}$ continuous tapered prep after cleaning and shaping of a root canal.

Root canal therapy $=$ is the removal, cleaning, shaping and obturation of the root canal space. 
Root canal retreatment $=$ is redoing a previously treated root canal tooth with the goal of a successful case.

Patency $=$ ability of having a clear path from canal orifice through the entire canal and through the apex of the tooth.

Endodontic sealer $=$ material used to fill in the voids the core material cannot fill.

Endodontic solvent $=$ solution used to soften or dissolve root canal filling materials.

Gutta-percha $=$ the most commonly used endodontic core filling material.

Chloroform $=$ most common endodontic solvent used. Formula $=\mathrm{CHCl}_{3}$. Eucalyptol $=$ the second most common endodontic solvent used. Formula $=$ $\mathrm{C}_{10} \mathrm{H}_{18} \mathrm{O}$.

Endosolv $\mathrm{R}=$ newer solvent designed for removing phenolic resin obturating materials. Composition $=33.5 \%$ Phenylethylic alcohol; $66.5 \%$ Formamida.

Mixing time $=$ the part of the mixing time required in order to obtain satisfactory mix of components. 
Setting time $=$ period of time measured from the end of mixing until the sealer has set according to the conditions of the manufacturer.

$\mathrm{AH}$ Plus $=$ an epoxy resin sealer produced by Caulk.

Epiphany = a dual cure, hydrophilic resin sealer by Pentron. Is to be used with Resilon. Methacrylate formula.

Resilon $=$ a new synthetic material based on polymers of polyester. Used as a core root canal filling material. Looks and handles like gutta-percha.

Manufactured by Pentron.

EndoREZ $=$ a self priming, hydrophilic, dual cure resin sealer produced by Ultradent. Methacrylate formula.

Roth's 801 Elite Grade $=$ a zinc-oxide and eugenol sealer that is a Grossman's formula sealer produced by Roth International.

\section{Assumptions}

(1) Sealer sets as it does in prepared root canals. (2) Endodontic solvent dissolves sealer as it does during retreatment. (3) Sealer removal increases the success of root canal retreatment. 


\section{Limitations}

(1) This in-vitro study mimics what happens in clinical retreatment of endodontic fillings. (2) Ratios of sealer and solvent are clinically relevant.

\section{Delimitations}

(1) Only large sizes of sealer were mixed in order to obtain recordable weights. (2) Sealers were allowed to set up for at least forty eight hours. (3) Only four sealers were tested. (4) Only three solvents were tested. 


\title{
Chapter 2
}

\section{Review of Literature}

\begin{abstract}
Although several studies (Torabinejad et al 2005, Hoskinson et al 2002, Marquis et al 2006) have concluded the success rate of root canal therapy is quite high, endodontic retreatment is a common procedure in endodontics (Weiger et al 1998). Root canal retreatment is an increasing element in endodontic practice (Hepworth and Friedman 1997, Koch 1997). A few reasons (Stabnolz et al 1994) for retreatment are missed canals, separated instruments, poor coronal or apical seal (Saunders and Saunders 1994), inadequate debridement and/or filling of the root canal space, and inadequate chemical irrigation. Depending on a variety of circumstances, the clinician must decide between surgical or nonsurgical retreatment. Today, the most commonly used endodontic filling material is gutta-percha and a sealer. Endodontic sealer comes in a variety of compositions: calcium hydroxide, zinc oxide and eugenol, silicon-based, glass ionomer, and resin sealers. Resin sealers are the newest composition of sealer. Sealer is used because gutta-percha alone cannot fill the three dimensional root canal system completely (Nguyen 1994, Schafer 2000). Regardless of the method of obturation, sealer is expressed laterally and apically, leaving it as the last
\end{abstract}


obstacle for a clinician to obtain patency during retreatment. It is a basic requirement of root filling materials, both core and sealer materials, that they can be removed or retreated (Grossman et al 1988). Lately, there has been a large number of studies looking at the leakage of resin sealers, but none have addressed their solubility in endodontic solvents.

Retreatment of previous root canal therapy includes locating all canals, removal of all previous root canal filling (both gutta-percha and sealer), chemomechanical cleaning of canals, and filling the root canal system. There are different methods to perform endodontic retreament including thermal, mechanical, chemical, or a combination of the three (Stabholz et al 1994). The two most common endodontic solvents are chloroform and eucalyptol, with chloroform being the most popular and extremely effective for gutta-percha removal (Wilcox 1995, Kaplowitz 1990, Wilcox et al 1987). Chloroform has been found to be a carcinogen (Barbosa et al 1994, Reuber 1979), but deemed safe in the amounts used as a dental solvent (McDonald and Vire 1992, United States Drug Administration 1976). Recently (Edgar et al 2006), chloroform has been found to decrease the intracanal levels of cultivatable E. faecalis, which is a microorganism thought to be possibly a cause of failing root canal therapy. Eucalyptol is also effective and safe (Hansen 1998, Zakariasen et al 1990, 
Uemura et al 1997, Wourms et al 1990). Although solvents for the removal of gutta-percha has been well studied, the solubility of endodontic sealer in solvents has seen very few studies (Whitworth and Boursin 2000).

Solubility refers to the ability for a given substance, the solute, to dissolve in a solvent. It usually is expressed as grams of solute per litre of solvent. In general, solubilities of solids in liquids increase with temperature and those of gases decrease with temperature and increase with pressure (Atkins and De Paula 2001).

In this study the endodontic sealers were the solutes and chloroform, eucalyptol, or Endosolv R were the solvents. This study followed the International Standard \#6876 (2001) specifications for testing root-canal sealing materials, although the focus was slightly different. The ISO \#6876 was to standardize looking at sealers, to test their solubility, and sets the standard so that sealers will not dissolve in water, salvia, or saline. 


\section{CHAPTER III}

\section{MATERIALS AND METHODS}

\section{SAMPLE DESCRIPTION}

Four sealers (Roth's Elite 801, AH Plus, Epiphany, EndoREZ) were all mixed according to the manufactor's specifications. There were 45 test samples of each sealer placed into metal rings with openings of a diameter of twenty millimeters and height of two millimeters. These samples were allowed to set up for at least forty eight hours or more at thirty seven degrees Celsius with moisture present. The samples of Roth's took twenty five days to set up. Prior to creating the samples, the metal rings were cleaned with acetone in an ultrasonic cleaner for twenty minutes. New rings were used for each sealer group being tested. The sample was deemed completely set up when a clean explorer would not penetrate into the test sample. Each sample was assigned a number, which was carved into the metal ring. Also, a hole was placed at the top of the ring to allow for suspension in solvent. 
Table 1. Sample Design

\begin{tabular}{|c|c|c|c|c|c|}
\hline & AH Plus & Epiphany & EndoREZ & Roth's801 & Control \\
\hline $\begin{array}{c}\text { Eucalyptol } \\
5 \text { mins }\end{array}$ & 5 & 5 & 5 & 5 & 0 \\
\hline $\begin{array}{c}\text { Eucalyptol } \\
10 \text { mins }\end{array}$ & 5 & 5 & 5 & 5 & 0 \\
\hline $\begin{array}{c}\text { Eucalyptol } \\
20 \text { mins }\end{array}$ & 5 & 5 & 5 & 5 & 4 \\
\hline $\begin{array}{c}\text { Chloroform } \\
5 \text { mins }\end{array}$ & 5 & 5 & 5 & 5 & 0 \\
\hline $\begin{array}{c}\text { Chloroform } \\
10 \text { mins }\end{array}$ & 5 & 5 & 5 & 5 & 0 \\
\hline $\begin{array}{c}\text { Chloroform } \\
20 \text { mins }\end{array}$ & 5 & 5 & 5 & 5 & 4 \\
\hline $\begin{array}{c}\text { Endosolv- } \\
\text { R 5 mins }\end{array}$ & 5 & 5 & 5 & 5 & 0 \\
\hline $\begin{array}{c}\text { Endosolv- } \\
\text { R 10 mins }\end{array}$ & 5 & 5 & 5 & 5 & 0 \\
\hline $\begin{array}{c}\text { Endosolv- } \\
\text { R 20 mins }\end{array}$ & 5 & 5 & 5 & 5 & 4 \\
\hline
\end{tabular}

\section{SOLUBILITY METHODOLOGY}

The samples were weighed on a digital scale to 0.0001 of a gram.

Each sample was tested in one of the three solvents (Chloroform,

Eucalyptol, Endosolv R) for one of three different times (five minutes, ten minutes, or twenty minutes). After being removed from the solvent the samples were rinsed with distilled water and allowed to completely dry for twenty four hours. The samples were weighed again on the same devise. 
During both measurements the devise was tared back to zero prior to

weighing each sample. One control sample, which was a metal ring with no sealer, was tested for each of the sealer groups in each of the solvents for 20 minutes.

\section{DATA COLLECTION}

The results were collected and placed into an Excel spreadsheet. The difference between the before and the after weights of each sample was calculated.

\section{Table 2. Data Table}

Column1

EndoRez Sample \#1/Euc 5mins EndoRez Sample \#2/Euc 5mins EndoRez Sample \#3/Euc 5mins EndoRez Sample \#4/Euc 5mins EndoRez Sample \#5/Euc 5mins EndoRez Sample \#1/Euc 10mins EndoRez Sample \#2/Euc 10mins EndoRez Sample \#3/Euc 10mins EndoRez Sample \#4/Euc 10mins EndoRez Sample \#5/Euc 10mins EndoRez Sample \#1/Euc 20mins EndoRez Sample \#2/Euc 20mins EndoRez Sample \#3/Euc 20mins EndoRez Sample \#4/Euc 20mins EndoRez Sample \#5/Euc 20mins EndoRez Sample \#1/Chlor $5 \mathrm{mins}$ EndoRez Sample \#2/Chlor 5 mins EndoRez Sample \#3/Chlor 5mins EndoRez Sample \#4/Chlor 5mins EndoRez Sample \#5/Chlor 5mins EndoRez Sample \#1/Chlor 10mins

\begin{tabular}{rrr}
\multicolumn{1}{l}{ Before } & \multicolumn{1}{l}{ After } & \multicolumn{1}{r}{ Difference } \\
30.7651 & 30.76 & 0.0051 \\
31.8937 & 31.8894 & 0.0043 \\
29.9762 & 29.9706 & 0.0056 \\
33.4353 & 33.4292 & 0.0061 \\
35.0395 & 35.0342 & 0.0053 \\
34.3293 & 34.3047 & 0.0246 \\
30.4457 & 30.4184 & 0.0273 \\
28.9732 & 28.9511 & 0.0221 \\
32.3394 & 32.3167 & 0.0227 \\
31.0738 & 31.0482 & 0.0256 \\
32.9113 & 32.8769 & 0.0344 \\
30.4567 & 30.4266 & 0.0301 \\
29.7208 & 29.6867 & 0.0341 \\
32.6426 & 32.6016 & 0.041 \\
31.7345 & 31.7011 & 0.0334 \\
31.0426 & 30.9831 & 0.0595 \\
32.3341 & 32.2734 & 0.0607 \\
31.0477 & 30.9876 & 0.0601 \\
27.5321 & 27.4774 & 0.0547 \\
29.8642 & 29.8061 & 0.0581 \\
28.7963 & 28.7402 & 0.0561
\end{tabular}


EndoRez Sample \#2/Chlor 10mins

EndoRez Sample \#3/Chlor 10mins

EndoRez Sample \#4/Chlor 10mins

EndoRez Sample \#5/Chlor 10mins

EndoRez Sample \#1/Chlor 20mins

EndoRez Sample \#2/Chlor 20mins

EndoRez Sample \#3/Chlor 20mins

EndoRez Sample \#4/Chlor 20mins

EndoRez Sample \#5/Chlor 20mins

EndoRez Sample \#1/E-Solv 5mins

EndoRez Sample \#2/E-Solv 5mins

EndoRez Sample \#3/E-Solv 5mins

EndoRez Sample \#4/E-Solv 5mins

EndoRez Sample \#5/E-Solv 5mins

EndoRez Sample \#1/E-Solv 10mins

EndoRez Sample \#2/E-Solv 10mins

EndoRez Sample \#3/E-Solv 10mins

EndoRez Sample \#4/E-Solv 10mins

EndoRez Sample \#5/E-Solv 10mins

EndoRez Sample \#1/E-Solv 20mins

EndoRez Sample \#2/E-Solv 20mins

EndoRez Sample \#3/E-Solv 20mins

EndoRez Sample \#4/E-Solv 20mins

EndoRez Sample \#5/E-Solv 20mins

Test Ring Euc

Test Ring Chlor

Test Ring E-Res

Epiphany Sample \#1/Euc 5mins

Epiphany Sample \#2/Euc 5 mins

Epiphany Sample \#3/Euc 5mins

Epiphany Sample \#4/Euc 5mins

Epiphany Sample \#5/Euc 5mins

Epiphany Sample \#1/Euc 10mins

Epiphany Sample \#2/Euc 10mins

Epiphany Sample \#3/Euc 10mins

Epiphany Sample \#4/Euc 10mins

Epiphany Sample \#5/Euc 10mins

Epiphany Sample \#1/Euc 20mins

Epiphany Sample \#2/Euc 20mins

Epiphany Sample \#3/Euc 20mins

Epiphany Sample \#4/Euc 20mins

Epiphany Sample \#5/Euc 20mins

Epiphany Sample \#1/Chlor 5 mins

Epiphany Sample \#2/Chlor 5 mins

Epiphany Sample \#3/Chlor 5mins

Epiphany Sample \#4/Chlor 5mins

Epiphany Sample \#5/Chlor 5mins

$\begin{array}{rrr}34.0143 & 33.9565 & 0.0578 \\ 30.9876 & 30.9294 & 0.0582 \\ 27.3451 & 27.291 & 0.0541 \\ 29.4328 & 29.3773 & 0.0555 \\ 32.4569 & 32.3578 & 0.0991 \\ 29.0419 & 28.9432 & 0.0987 \\ 30.9432 & 30.8461 & 0.0971 \\ 35.6722 & 35.5729 & 0.0993 \\ 32.5238 & 32.4244 & 0.0994 \\ 29.6167 & 29.6133 & 0.0034 \\ 28.7757 & 28.7736 & 0.0021 \\ 29.9634 & 29.9598 & 0.0036 \\ 33.4511 & 33.447 & 0.0041 \\ 32.4532 & 32.4485 & 0.0047 \\ 33.4568 & 33.4489 & 0.0079 \\ 31.5218 & 31.5129 & 0.0089 \\ 29.6347 & 29.6266 & 0.0081 \\ 28.4911 & 28.4839 & 0.0072 \\ 30.2323 & 30.2264 & 0.0059 \\ 37.0453 & 37.0104 & 0.0349 \\ 29.1753 & 29.1346 & 0.0407 \\ 28.1454 & 28.1143 & 0.0311 \\ 30.9432 & 30.9101 & 0.0331 \\ 32.3567 & 32.324 & 0.0327 \\ 32.0762 & 32.0762 & 0 \\ 31.9838 & 31.9839 & -1 \mathrm{E}-04 \\ 36.2781 & 36.2782 & -1 \mathrm{E}-04\end{array}$

$\begin{array}{lll}32.8657 & 32.8653 & 0.0004 \\ 29.7661 & 29.7658 & 0.0003 \\ 32.4512 & 32.4505 & 0.0007 \\ 30.0853 & 30.0851 & 0.0002 \\ 28.4115 & 28.4113 & 0.0002 \\ 31.7811 & 31.7802 & 0.0009 \\ 32.4356 & 32.4349 & 0.0007 \\ 29.8867 & 29.8856 & 0.0011 \\ 35.6321 & 35.6309 & 0.0012 \\ 30.9432 & 30.9426 & 0.0006 \\ 33.4534 & 33.4526 & 0.0008 \\ 32.0563 & 32.0552 & 0.0011 \\ 29.9579 & 29.9572 & 0.0007 \\ 31.4523 & 31.4518 & 0.0005 \\ 26.5623 & 26.5616 & 0.0007 \\ 29.4382 & 29.4117 & 0.0265 \\ 30.4532 & 30.4321 & 0.0211 \\ 32.6579 & 32.6276 & 0.0303 \\ 36.0012 & 35.9733 & 0.0279 \\ 28.7221 & 28.6943 & 0.0278\end{array}$


Epiphany Sample \#1/Chlor 10mins Epiphany Sample \#2/Chlor 10mins Epiphany Sample \#3/Chlor 10mins Epiphany Sample \#4/Chlor 10mins Epiphany Sample \#5/Chlor 10mins Epiphany Sample \#1/Chlor 20mins Epiphany Sample \#2/Chlor 20mins Epiphany Sample \#3/Chlor 20mins Epiphany Sample \#4/Chlor 20mins Epiphany Sample \#5/Chlor 20mins Epiphany Sample \#1/E-Solv 5mins Epiphany Sample \#2/E-Solv 5mins Epiphany Sample \#3/E-Solv 5mins Epiphany Sample \#4/E-Solv 5mins Epiphany Sample \#5/E-Solv 5mins Epiphany Sample \#1/E-Solv 10mins Epiphany Sample \#2/E-Solv 10mins Epiphany Sample \#3/E-Solv 10mins Epiphany Sample \#4/E-Solv 10mins Epiphany Sample \#5/E-Solv 10mins Epiphany Sample \#1/E-Solv 20mins Epiphany Sample \#2/E-Solv 20mins Epiphany Sample \#3/E-Solv 20mins Epiphany Sample \#4/E-Solv 20mins Epiphany Sample \#5/E-Solv 20mins Test Ring Euc Test Ring Chlor Test Ring E-Res

AH Plus Sample \#1/Euc 5mins AH Plus Sample \#2/Euc 5 mins AH Plus Sample \#3/Euc 5mins AH Plus Sample \#4/Euc 5 mins AH Plus Sample \#5/Euc 5mins AH Plus Sample \#1/Euc 10mins AH Plus Sample \#2/Euc 10mins AH Plus Sample \#3/Euc 10mins AH Plus Sample \#4/Euc 10mins AH Plus Sample \#5/Euc 10mins AH Plus Sample \#1/Euc 20mins AH Plus Sample \#2/Euc 20mins AH Plus Sample \#3/Euc 20mins AH Plus Sample \#4/Euc 20mins AH Plus Sample \#5/Euc 20mins AH Plus Sample \#1/Chlor 5 mins AH Plus Sample \#2/Chlor 5 mins AH Plus Sample \#3/Chlor $5 \mathrm{mins}$ AH Plus Sample \#4/Chlor 5 mins

$\begin{array}{rrr}31.3347 & 31.2561 & 0.0786 \\ 32.8436 & 32.7603 & 0.0833 \\ 29.0443 & 28.9682 & 0.0761 \\ 32.1789 & 32.1017 & 0.0772 \\ 33.1148 & 33.0355 & 0.0793 \\ 34.3217 & 34.2423 & 0.0794 \\ 30.6473 & 30.58 & 0.0673 \\ 27.6653 & 27.5879 & 0.0774 \\ 29.6547 & 29.5656 & 0.0891 \\ 31.5732 & 31.4849 & 0.0883 \\ 33.7686 & 33.7475 & 0.0211 \\ 29.1445 & 29.1211 & 0.0234 \\ 30.1045 & 30.0836 & 0.0209 \\ 36.4126 & 36.3927 & 0.0199 \\ 34.3223 & 34.3006 & 0.0217 \\ 31.4359 & 31.4131 & 0.0228 \\ 33.4397 & 33.4156 & 0.0241 \\ 27.6113 & 27.5882 & 0.0231 \\ 30.4571 & 30.437 & 0.0201 \\ 28.6732 & 28.6511 & 0.0221 \\ 29.8217 & 29.798 & 0.0237 \\ 36.5117 & 36.4886 & 0.0231 \\ 30.7327 & 30.7126 & 0.0201 \\ 28.7641 & 28.7398 & 0.0243 \\ 33.4894 & 33.4638 & 0.0256 \\ 32.0763 & 32.0762 & 0.0001 \\ 31.9838 & 31.9838 & 0 \\ 36.2782 & 36.2783 & -0.0001\end{array}$

$\begin{array}{rrr}29.6403 & 29.6347 & 0.0056 \\ 33.3673 & 33.3621 & 0.0052 \\ 35.0353 & 35.0306 & 0.0047 \\ 33.297 & 33.2907 & 0.0063 \\ 36.0991 & 36.092 & 0.0071 \\ 30.451 & 30.4431 & 0.0079 \\ 30.9722 & 30.9639 & 0.0083 \\ 34.9017 & 34.8926 & 0.0091 \\ 36.9233 & 36.9162 & 0.0071 \\ 23.4756 & 23.4679 & 0.0077 \\ 31.917 & 31.8819 & 0.0351 \\ 29.6301 & 29.6004 & 0.0297 \\ 35.9459 & 35.9127 & 0.0332 \\ 34.7695 & 34.7312 & 0.0383 \\ 34.8782 & 34.8411 & 0.0371 \\ 30.9505 & 30.5906 & 0.3599 \\ 30.6808 & 30.2686 & 0.4122 \\ 30.3987 & 30.0224 & 0.3763 \\ 30.377 & 29.9828 & 0.3942\end{array}$


AH Plus Sample \#5/Chlor 5 mins AH Plus Sample \#1/Chlor 10mins AH Plus Sample \#2/Chlor 10mins AH Plus Sample \#3/Chlor 10mins AH Plus Sample \#4/Chlor 10mins AH Plus Sample \#5/Chlor 10mins AH Plus Sample \#1/Chlor 20mins AH Plus Sample \#2/Chlor 20mins AH Plus Sample \#3/Chlor 20mins AH Plus Sample \#4/Chlor 20mins AH Plus Sample \#5/Chlor 20mins AH Plus Sample \#1/E-Solv 5 mins AH Plus Sample \#2/E-Solv 5mins AH Plus Sample \#3/E-Solv 5mins AH Plus Sample \#4/E-Solv 5 mins AH Plus Sample \#5/E-Solv 5mins AH Plus Sample \#1/E-Solv 10 mins AH Plus Sample \#2/E-Solv 10 mins AH Plus Sample \#3/E-Solv 10 mins AH Plus Sample \#4/E-Solv $10 \mathrm{mins}$ AH Plus Sample \#5/E-Solv 10 mins AH Plus Sample \#1/E-Solv 20mins AH Plus Sample \#2/E-Solv 20mins AH Plus Sample \#3/E-Solv 20mins AH Plus Sample \#4/E-Solv 20mins AH Plus Sample \#5/E-Solv 20mins Test Ring Euc Test Ring Chlor Test Ring E-Res

Roth's Sample \#1/ Euc 5mins Roth's Sample \#2/ Euc 5mins Roth's Sample \#3/ Euc 5mins Roth's Sample \#4/ Euc 5mins Roth's Sample \#5/ Euc 5mins Roth's Sample \#1/ Euc 10mins Roth's Sample \#2/ Euc 10mins Roth's Sample \#3/ Euc 10mins Roth's Sample \#4/ Euc 10mins Roth's Sample \#5/ Euc 10mins Roth's Sample \#1/ Euc 20mins Roth's Sample \#2/ Euc 20mins Roth's Sample \#3/ Euc 20mins Roth's Sample \#4/ Euc 20mins Roth's Sample \#5/ Euc 20mins Roth's Sample \#1/ Chlor 5mins Roth's Sample \#2/ Chlor 5mins Roth's Sample \#3/ Chlor 5mins

$\begin{array}{rrr}32.2863 & 31.9396 & 0.3467 \\ 29.4834 & 28.8585 & 0.6249 \\ 31.383 & 30.7092 & 0.6738 \\ 36.6017 & 35.9631 & 0.6386 \\ 32.5594 & 31.9253 & 0.6341 \\ 29.7727 & 29.1608 & 0.6119 \\ 30.6044 & 29.3836 & 1.2208 \\ 33.4172 & 31.9844 & 1.4328 \\ 34.9437 & 33.724 & 1.2197 \\ 30.3995 & 29.2879 & 1.1116 \\ 31.8261 & 30.7329 & 1.0932 \\ 34.5871 & 34.5862 & 0.0009 \\ 30.3583 & 30.357 & 0.0013 \\ 29.6166 & 29.6159 & 0.0007 \\ 34.685 & 34.6837 & 0.0013 \\ 30.2384 & 30.2373 & 0.0011 \\ 29.7536 & 29.7528 & 0.0008 \\ 29.9512 & 29.9508 & 0.0004 \\ 27.2891 & 27.288 & 0.0011 \\ 35.3411 & 35.3403 & 0.0008 \\ 32.3527 & 32.352 & 0.0007 \\ 27.4867 & 27.4839 & 0.0028 \\ 35.6864 & 35.6847 & 0.0017 \\ 35.7368 & 35.7359 & 0.0009 \\ 32.7565 & 32.7531 & 0.0034 \\ 34.0519 & 34.0493 & 0.0026 \\ 32.0762 & 32.0762 & 0 \\ 31.9838 & 31.9839 & -1 \mathrm{E}-04 \\ 36.2783 & 36.2782 & 0.0001\end{array}$

$\begin{array}{rrr}31.8717 & 31.6498 & 0.2219 \\ 32.4731 & 32.1938 & 0.2793 \\ 30.291 & 30.1001 & 0.1909 \\ 29.3689 & 29.1681 & 0.2008 \\ 33.7641 & 33.5468 & 0.2173 \\ 31.8269 & 31.6364 & 0.1905 \\ 30.6425 & 30.4251 & 0.2174 \\ 28.9939 & 28.7464 & 0.2475 \\ 32.3471 & 32.1608 & 0.1863 \\ 34.0728 & 33.8152 & 0.2576 \\ 32.0614 & 31.843 & 0.2184 \\ 33.6841 & 33.3947 & 0.2894 \\ 30.9438 & 30.7452 & 0.1986 \\ 31.7892 & 31.5327 & 0.2565 \\ 32.4563 & 32.2199 & 0.2364 \\ 37.6086 & 37.2532 & 0.3554 \\ 35.7182 & 35.4008 & 0.3174 \\ 34.7683 & 34.3721 & 0.3962\end{array}$


Roth's Sample \#4/ Chlor 5 mins Roth's Sample \#5/ Chlor 5mins Roth's Sample \#1/ Chlor 10mins Roth's Sample \#2/ Chlor 10mins Roth's Sample \#3/ Chlor 10mins Roth's Sample \#4/ Chlor 10mins Roth's Sample \#5/ Chlor 10mins Roth's Sample \#1/ Chor 20mins Roth's Sample \#2/ Chlor 20mins Roth's Sample \#3/ Chlor 20mins Roth's Sample \#4/ Chlor 20mins Roth's Sample \#5/ Chor 20mins Roth's Sample \#1/ E-Solv 5mins Roth's Sample \#2/ E-Solv 5mins Roth's Sample \#3/ E-Solv 5mins Roth's Sample \#4/ E-Solv 5mins Roth's Sample \#5/ E-Solv 5mins Roth's Sample \#1/ E-Solv 10mins Roth's Sample \#2/ E-Solv 10mins Roth's Sample \#3/ E-Solv 10mins Roth's Sample \#4/ E-Solv 10mins Roth's Sample \#5/ E-Solv 10mins Roth's Sample \#1/ E-Solv 20mins Roth's Sample \#2/ E-Solv 20mins Roth's Sample \#3/ E-Solv 20mins Roth's Sample \#4/ E-Solv 20mins Roth's Sample \#5/ E-Solv 20mins Test Ring Euc Test Ring Chlor Test Ring E-Res

$\begin{array}{rrr}29.0384 & 28.6642 & 0.3742 \\ 30.4117 & 30.0456 & 0.3661 \\ 37.3149 & 36.8998 & 0.4151 \\ 34.4762 & 34.0915 & 0.3847 \\ 32.5379 & 32.0707 & 0.4672 \\ 35.4118 & 34.9645 & 0.4473 \\ 29.9982 & 29.5615 & 0.4367 \\ 35.741 & 34.6784 & 1.0626 \\ 33.1026 & 32.0847 & 1.0179 \\ 32.8432 & 31.5143 & 1.3289 \\ 29.0973 & 27.9249 & 1.1724 \\ 34.3546 & 33.3577 & 0.9969 \\ 36.5189 & 36.4757 & 0.0432 \\ 31.7653 & 31.7207 & 0.0446 \\ 29.7891 & 29.738 & 0.0511 \\ 34.5724 & 34.5346 & 0.0378 \\ 32.4867 & 32.4475 & 0.0392 \\ 34.8801 & 34.8246 & 0.0555 \\ 32.5726 & 32.5189 & 0.0537 \\ 30.8917 & 30.8336 & 0.0581 \\ 33.8671 & 33.8104 & 0.0567 \\ 35.1478 & 35.0966 & 0.0512 \\ 34.5016 & 34.4519 & 0.0497 \\ 29.6437 & 29.592 & 0.0517 \\ 32.3282 & 32.2806 & 0.0476 \\ 31.7664 & 31.7181 & 0.0483 \\ 34.6789 & 34.6269 & 0.052 \\ 32.0763 & 32.0764 & -1 \mathrm{E}-04 \\ 31.9837 & 31.9836 & 1 \mathrm{E}-04 \\ 36.2782 & 36.2781 & 1 \mathrm{E}-04\end{array}$

\section{DATA ANALYSIS}

The data was analyzed in a Split Plot Model with the REML

(Restricted or Residual Maximum Likelihood Method) and Tukey's HSD

anaylsis. This was accomplished, by using the Jump software, with the help

of a statistician. Significance was determined at $\mathrm{P}<0.05$. A one-way

ANOVA was also used to determine if a significant difference existed 
between groups and Tukey's HSD test used to identify which groups were significantly different. Significance was determine at $\mathrm{P}<0.05$. The Tukey analysis was also used to determine statistical differences between by sealers, solvents, and times.

\section{MATERIALS AND EQUIPMENT}

- Endosolv R (Septodont, Cedex France)

- Chloroform (Sultan Healthcare Inc., Englewood NJ)

- Eucalyptol (Sultan Healthcare Inc., Englewood NJ)

- 5/8 Flat Washers (Hillman Group Inc., Cincinnati OH)

- EndoREZ (Ultradent, South Jordan UT)

- AH Plus (Dentsply Maillefer, Tulsa OK)

- Epiphany (Pentron Clinical, Wallinford CT)

- Roth's Elite Grade 801 (Roth International, Chicago IL) 


\section{CHAPTER IV}

\section{RESULTS AND DISCUSSION}

\section{RESULTS}

The statistical analysis of the data was performed by a Split Plot Model within the REML method and a Tukey's HSD anaylsis. The results of this study did not support the null hypothesis, that there is no difference between four different endodontic sealers when testing for solubility in three different solvents. The results show the following factors are significant. Solubility depends on the sealer, solvent, and time. Solubility of the sealer depends on which solvent was used. Solubility depends on the effects of the solvent and time. 
Solubility of Sealer $(p=0.0028)$

AH Plus and Roth's are approximately twice as soluble than Epiphany and EndoREZ. Epiphany and EndoREZ were not soluble in any of the three solvents tested for.

Figure 1. Solubility of Sealers

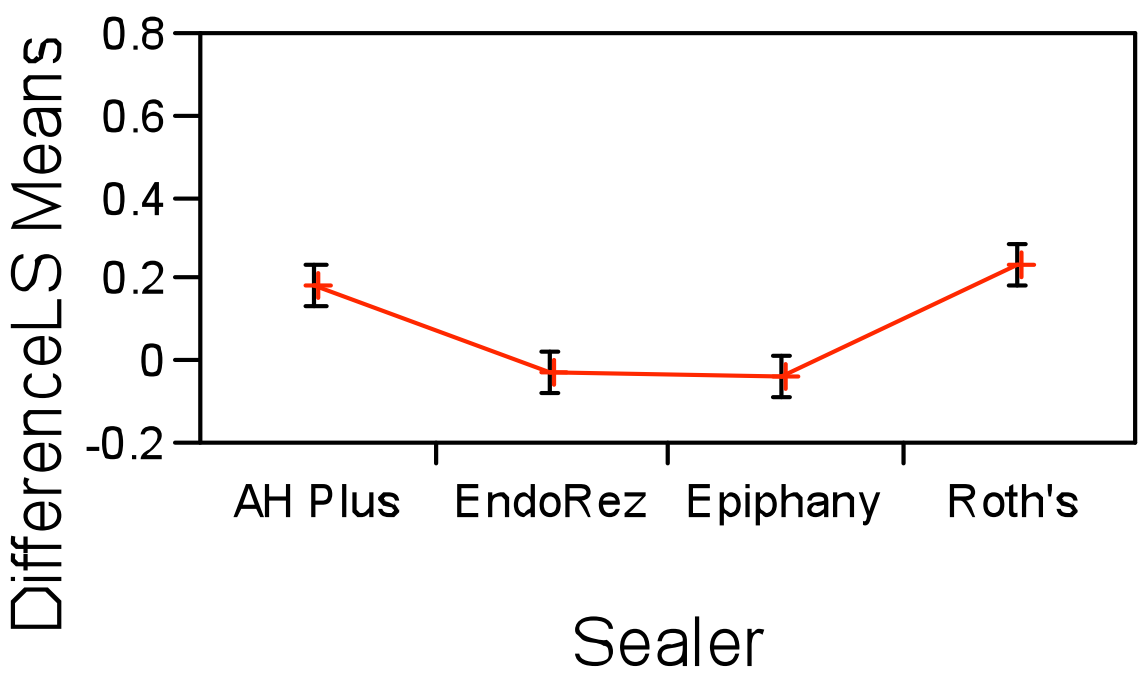

The sealers AH Plus and Roth's 801 were statistically significant compared to Epiphany and EndoREZ in the Tukey analysis.

Table 3. Oneway Analysis of Difference By Sealer

Level

Roth's

$\mathrm{AH}$ Plus

EndoRez

Epiphany

$\begin{array}{lrr} & \text { Mean } \\ \text { A } & & 0.30418222 \\ \text { A } & & 0.25363556 \\ & \text { B } & 0.03596667 \\ & \text { B } & 0.02834889\end{array}$




\section{Solubility of Sealer in Different Solvents}

AH Plus and Roth's were 6-7 times more soluble in chloroform than any other combination of sealer-solvent interaction. Also, Roth's was two times more soluble in Eucalyptol than Epiphany or EndoREZ was in any of the three tested solvents.

Fig 2. Solubility of Sealer in Different Solvents

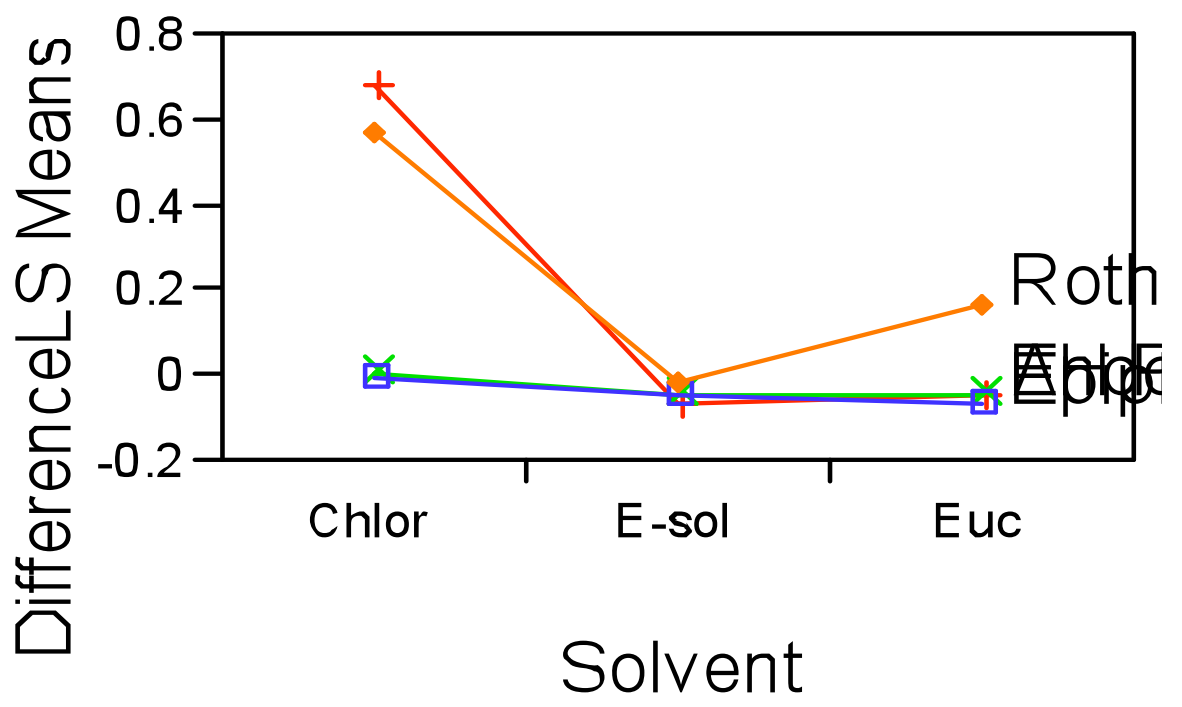




\section{Solvents Ability to Dissolve Endodontic Sealer $(p<0.0001)$}

Chloroform was three times more powerful at dissolving the four endodontic sealers tested than the other two solvents, Eucalyptol and Endosolv-R.

Although not significant, Eucalyptol was more effective than Endosolv-R.

Fig 3. Solvent Ability to Dissolve Endodontic Sealer

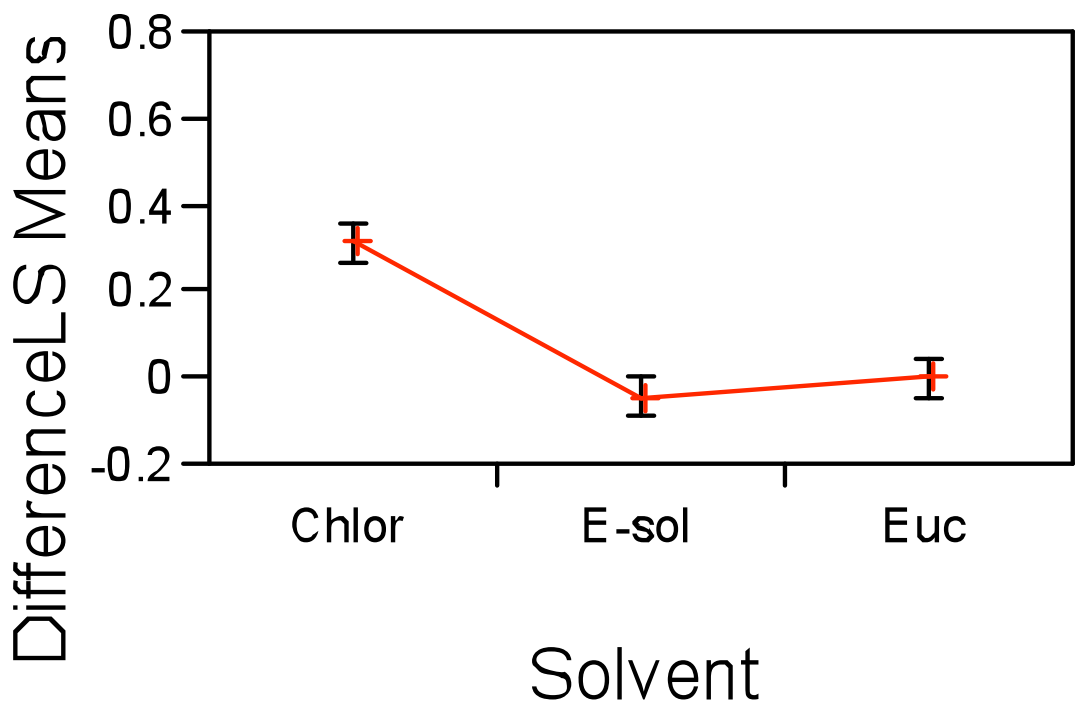

When the Tukey anaylsis evaluated the solvents, chloroform was statistically more effective than eucalyptol and Endosolv-R.

Table 4. Oneway Analysis of Difference By Solvent

Level

Chlor

Euc

E-sol
A

B

B
Mean

0.37812833

0.06638333

0.02208833 


\section{Solubility and Time}

As the solvent was allowed to interact with the sealer, the longer the time frame the more soluble the sealers became. This was a fairly steady linear relationship.

Fig 4. Solubility and Time

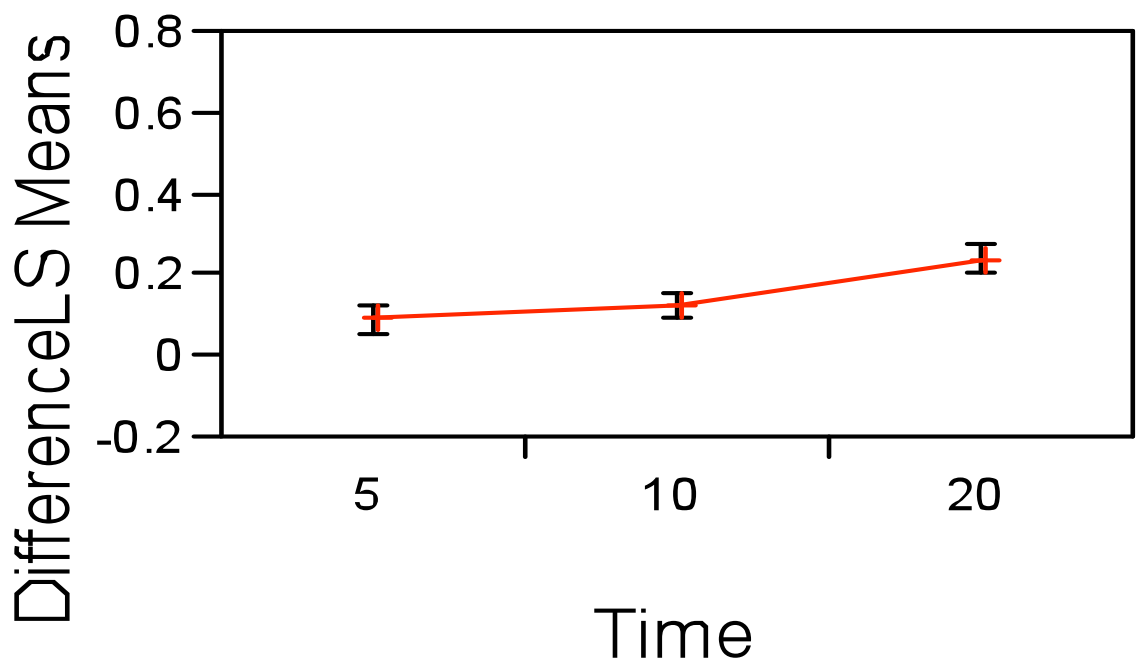

Allowing the solvent a longer time frame was significant. Twenty minutes was statistically more effective than five minutes, according to the Tukey analysis.

Table 5. Oneway Analysis of Difference By Time

Level

20

10

5
A

B
Mean

0.24419000

0.12843167

0.09397833 


\section{Time and Solvent Interaction $(p<0.0001)$}

Time and solvent interaction was significant, but it was one particular solvent (Chloroform) that caused this statistical significance. Chloroform was six times stronger than Eucalyptol and EndoSolv-R at the 20 minute time interval.

Fig 5. Time and Solvent Interaction

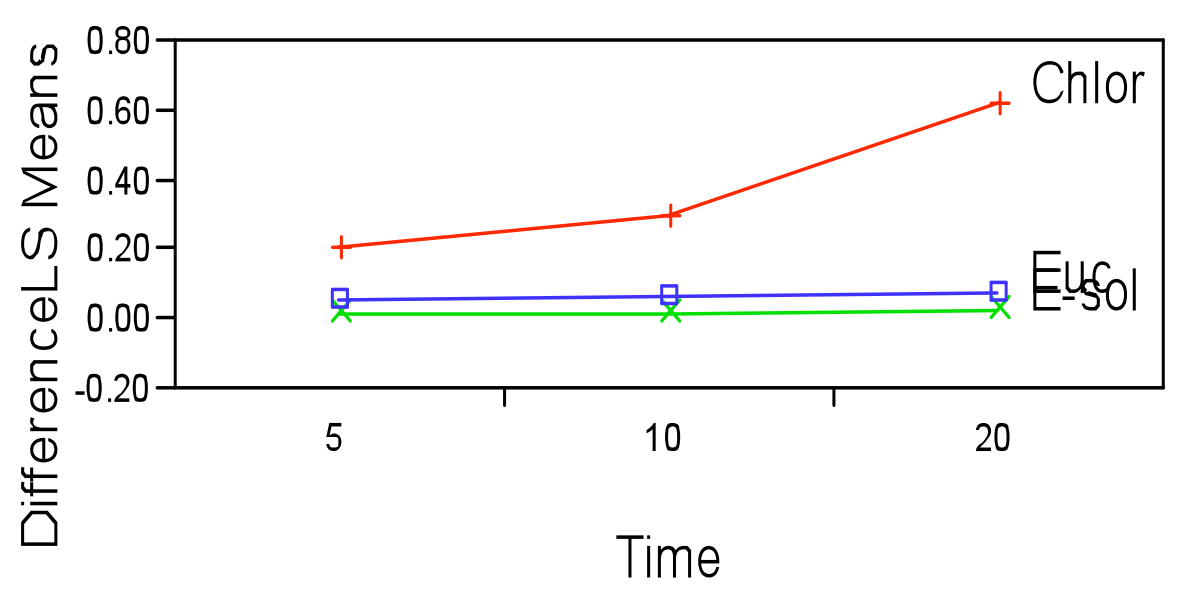




\section{DISCUSSION}

As dentistry and the population continue to grow, people will continue to seek better dental health care. The dental profession needs to have clinical research behind the products on the market. According to the results of this study, it indicates the need for more testing of new sealers and their solubility. Chloroform was capable of completely dissolving gutta-percha (Kaplowitz 1991) but did not test for any sealers. This study agrees with previously cited studies that chloroform is the most effective endodontic solvent. It has the capability of dissolving gutta-percha and some sealers, but two of the sealers tested in this study were not soluble in any of the three solvents. Chloroform is not ideal, because of it's poor biocompatibility (USFDA 1976) and decrease in dentin bonding strength (Erdemir et al 2004).

It is reasonable to understand the less leakage a sealer can provide the better, but what if it's not soluble? How can we as clinicians determine which solvent to use when we are blind to what sealer was initially used? These are questions that need to be addressed in the future with sound research, so that the success of retreatment does not decline. The current research on sealer solubility is very limited and is nonexistent for resin 
sealers. Hopefully, this current research begins to answer a few of our questions and stimulates more research in this topic. 


\section{CHAPTER V}

\section{SUMMARY AND CONCLUSIONS}

\section{SUMMARY}

The results of this study are multifaceted, because they point out the following observations. First, chloroform, especially used for twenty minutes, is the most effective solvent. Chloroform has been proven to completely dissolve gutta-percha and was the strongest against the four sealers in this experiment. AH Plus and Roth's 801 were much more soluble than EndoREZ and Epiphany, when tested against chloroform, eucalyptol, and Endosolv-R. EndoREZ and Epiphany were not soluble in any of the three solvents used in this study. Our recommendation is for future testing to find a suitable solvent for each of these sealers. Lastly, Endosolv-R was not effective at dissolving any of the four sealers in this experiment. Although it was designed to be used for removal of resorcinol-formaldehyde resin or "Russian Red" type sealers, some have a misunderstanding that it's for all resin sealers. Endosolv-R was not effective on any of the three resin sealers tested for. Although the results of this study do not include all resin sealers, it strongly suggests the need for resin sealers on the market to have their solubility tested. 


\section{CONCLUSIONS}

This study suggests the usage of chloroform as an endodontic solvent and the longer it is allowed to dissolve gutta-percha and sealer the softer those materials become. According to our data, Epiphany and EndoREZ should not be used unless an acceptable solvent can be found for them.

Lastly, Endosolv-R should only be used on resorcinol-formaldehyde resin, which is easily identifiable due to it's distinct color, and should not be used on the new resin sealers. 


\section{References}

Atkins PW, De Paula J. Atkin's Physical Chemistry. $7^{\text {th }}$ Edition. New York, W.H. Freeman \& Co.: 2001. pg 163-189.

Barbosa SV, Burkard DH, Spangberg LS. Cyctotoxic effects of gutta-percha solvents. J Endodon 1994; 20: 6.

Edgar SW, Marshall JG, Baumgartner JC: The antimicrobial effect of chloroform of Enterococcus faecalis after gutta-percha removal. J Endodon 2006; 32(12): 1185-7.

Erdemir A, Eldeniz AU, Belli S, Pashley DH. Effects of Solvents of Bonding to Root Canal Dentin. J Endodon 2004; 30(8): 589-92.

Grossman LLI, Oliet S, del Rio CE. Endodontics. 11 th ed. Philadelphia, PA: Lea and Febiger: 1998. pg 242-70.

Hansen MG. Relative efficiency of solvents used in endodontics. $J$ Endodon 1998; 24: 38-40.

Hepworth MJ, Friedman S. Treatment outcome of surgical and non-surgical management of endodontic failures. J Canad Dent Assoc 1997; 63: 364-71.

Hoskinson SE, Ng YL, Hoskinson AE, Moles DR, Gulabivala K. A retrospective comparasion of outcome of root canal treatment using two different protocols. Oral Surg Oral Med Oral Patholo 2002; 93(6): 705-15.

International Organization for Standardization. International Standard ISO 6876: dental root canal sealing materials. 2001.

Kaplowitz, GJ. Evaluation of the Ability of Essential Oils to Dissolve Gutta-Percha. J Endodon 1991; 17(9): 448-9.

Koch H. The microscope: It's effect on your practice. Dent Clin N America 1997; 41: 619-26.

Marquis VL, Dao T, Farzaneh M, Abitbol S, Friedman S. Treatment Outcomes in Endodontics: The Toronto Study. Phase III: Initial Treatment. J Endodon 2006; 32(4): 299-306. 
McDonald MN and Vire DE. Chloroform in the Endodontic operatory. $J$ Endodon 1992;18: 301.

Nguyen TN. Obturation of the root canal system. In: Cohen S, Burns RC, editors. Pathways of the pulp. 6 th ed. St. Louis: Mosby; 1994; pg 219-71.

Reuber MD. Carcinogenicity of chloroform. Environ Health Persect 1979; 31: 171-82.

Saunders WP, Saunders EM. Coronal leakage as a cause of failure in root canal therapy: a review. Endod Dent Traumatol 1994; 10: 105-8.

Schafer E. Root filling materials. Dtsch Zahnarztl Z 2000; 55: 15-25.

Stabholz A, Friedman S, Tames A. Endodontic failures and retreatment. In: Cohen S, Burns RC, editors. Pathways of the pulp. 6 th ed. St. Louis: Mosby; 1994. pg 690-728.

Torabinejad M, Kutesenko D, Machnick TK, Ismail A, Newtoan CW. Levels of Evidence for the Outcome of Nonsurgical Endodontic Treatment. J Endodon 2005; 31(9): 637-46.

Uemura M, Hata G, Toda T, Weine FS. Effectiveness of Eucalyptol and $d$ Limonene as gutta-percha solvents. J Endodon 1997; 23: 739-41.

United States Drug Administration. Chloroform Used as an Ingredient (active or inactive) in Drug Products. U.S. Government Printing Office 1976; Washington, DC.

Weiger R, Axmann-Kremar D, Lost C: Prognosis of conventional root canal treatment reconsidered. Endodo Dent Traumatol 1998; 14: 1-9.

Whitworth JM, Boursin EM. Dissolution of root canal sealer cements in volatile solvents. Int Endod J 2000; 33: 19-24.

Wilcox LR. Endodontic retreatment: ultrasonics and chloroform solvent. $J$ Endodon 1995; 13: 453-7. 
Wilcox LR, Krell DV, Madison S, Rittman B. Endodontic retreatment: evaluation of gutta-percha and sealer removal and canal reinstrumentation. $J$ Endodon 1987; 13: 435.

Wourms DJ, Campbell AD, Hicks ML, Pelleu GB. Alternative solvents to chloroform for gutta-percha removal. J Endodon 1990; 16: 224-6.

Zakariasen KL, Brayton SM, Collinson DM. Efficient and effective root canal retreatment without chloroform. J Can Dent Assoc 1990; 56: 509. 


\section{CURRICULUM VITAE}

\section{Ryan W.L. Burleson}

118 Thistledown Ln Morgantown, WV 26508

Objective

Summary

Education

Experience

\section{References}

After obtaining my D.D.S. from West Virginia University School of Dentistry in 2002, I began to practice general dentistry with my father. I am currently enrolled in the Endodontic residency at WVU and will finish the program in 2008.

I am currently establishing a private practice limited to endodontics in the city of Apex, NC.

Miami University, Oxford, Ohio 1995-1998

West Virginia University, Morgantown, WV 1998-2002

West Virginia University, Endodontic Residency, 2006-2008

Burleson Dental Practice, LLC; 2002-present Dentist, Partner

- Participant of the State of Ohio Scioto County Sealant Public Health Program.

- Associate of the Ohio Department of Health's Bureau for Children with Medical Handicaps.

WVU Department of Endodontics; 2006- present Endodontic Resident

- Will obtain a M.S. from an Accredited Program of Endodontics

Linda and Bill Ray, DDS, PLLC; 2007-present Dentist, Associate

- Performed endodontic therapy and managed staff. 